\title{
Investigating the role of volatile sources in the 1991 eruption of Mount Pinatubo (Philippines)
}

\author{
MELISSA J DRIGNON ${ }^{1}$, FEDERICA SCHIAVI ${ }^{2}$, WEIRAN \\ LI $^{3}$, NICOLAS CLUZEL ${ }^{2}$ AND CAROLINE BOUVET DE \\ MAISONNEUVE $^{1}$ \\ ${ }^{1}$ Nanyang Technological University \\ ${ }^{2}$ Université Clermont Auvergne \\ ${ }^{3}$ University of Cambridge \\ Presenting Author: melissa.drignon@ntu.edu.sg
}

Thirty years ago, Mount Pinatubo abruptly ended a 500-year period of dormancy with a VEI 6 Plinian eruption, constituting one of the most violent eruptions of the $20^{\text {th }}$ century. The early phases erupted two andesites (lava and scoria) that contained basaltic enclaves and released large amounts of $\mathrm{SO}_{2}$ into the atmosphere. The climatic phase of June $15^{\text {th }}, 1991$ alone released 17-20 Mt of $\mathrm{SO}_{2}$ into the atmosphere and erupted two types of dacitic pumices. Over the course of the eruption, the $\mathrm{SO}_{2}$ release was superior by several orders of magnitude to the concentration that can be dissolved into the erupted magmas and cooled the Earth's climate by $0.4-0.6{ }^{\circ} \mathrm{C}$ during the next two years. The source(s) of that excess sulfur release remains controversial today.

We investigated the origins of the sulfur and other volatiles involved in the eruption by analyzing both the volatile concentrations $\left(\mathrm{H}_{2} \mathrm{O}, \mathrm{CO}_{2}, \mathrm{~S}, \mathrm{Cl}, \mathrm{F}\right)$ and sulfur isotopes $\left(\delta^{34} \mathrm{~S}\right)$ of quartz- and plagioclase-hosted melt inclusions from the basalt, andesites and dacites. The melt inclusions were homogenized at 1-atm, and both their glass and vapor bubbles were analyzed for volatiles. We also mapped and analyzed the $\mathrm{S}, \mathrm{F}$, and $\mathrm{Cl}$ concentrations in apatite crystals of both the pre-climatic and climatic phases. The groundmass apatite crystals in basaltic inclusions are, on average, more enriched in S (4000 ppm- $>1$ wt.\%) and depleted in $\mathrm{F}$ and $\mathrm{Cl}$ compared to the apatite crystals in andesitic and dacitic samples. In addition, we analyzed the compositions of amphibole and plagioclase crystals from the different eruptive phases to better constrain the reservoirs' P-T$\mathrm{H}_{2} \mathrm{O}-\mathrm{fO}_{2}$ conditions with more recent geothermobarohygrometers. Finally, Ti-in-quartz diffusion modelling and CL mapping revealed that the cooling, highly crystallized, upper reservoir was remobilized over the century to decades prior to the eruption. 